\title{
Quantification of Flavonoides and Phenols of Bravo Bean Extract (Capparis flexuosa L. Caparaceae)
}

\author{
Anderson Soares de Almeida ${ }^{1 *}$ and Aldenir Feitosa dos Santos ${ }^{2}$ \\ ${ }^{1}$ Graduate Program in Pharmaceutical Sciences, Federal University of Sergip São Cristovão, SE, Sergipe, Brazil \\ ${ }^{2}$ State University of Alagoas, UNEAL and University Center, Cruzeiro, Arapiraca, AL, Brazil \\ *Corresponding author: Anderson Soares de Almeida, Graduate Program in Pharmaceutical Sciences, Federal University \\ of Sergip São Cristovão, SE, Sergipe, Brazil
}

\section{ARTICLE INFO}

Received: 慧 October 25, 2021

Published: 幽 November 08, 2021

\section{ABSTRACT}

Citation: Anderson Soares de Almeida, Aldenir Feitosa dos Santos. Quantification of Flavonoides and Phenols of Bravo Bean Extract (Capparis flexuosa L. Caparaceae). Biomed J Sci \& Tech Res 39(5)-2021. BJSTR. MS.ID.006358.

\section{Introduction}

The use of plants for medicinal purposes is not present only in contemporaneity, since the course of human history there was already the search for plants that possessed the curative capacity, even with little knowledge about them, the men of antiquity already used them and distinguished them for the various purposes. Medicinal herbs are fundamental in the treatment of various pathologies, especially in communities isolated from large urban centers [1]. With the advent of navigations it was possible to discover new continents, presenting to the world the great therapeutic arsenal derived from plants, indispensable to modern medicine [2]. Nature has always been a source of charm for man, not only for the useful resources of its food and maintenance, but for being its greatest source of learning and inspiration [3]. Brazil is a privileged country in biodiversity since, of all the plant species in the world, $20 \%$ is in The Brazilian territory. Several native or nonnative species face risk of extinction due to the degradation of their habitat and exploratory [4].

Although Brazil has a great biodiversity, there are still few species cataloged and strictly studied as their therapeutic potential, which makes it difficult to make use of these. However, ethnobotany research in the Northeast has shown satisfactory results, especially of plants adapted in the caatinga [5]. The caatinga biome is present only in The Brazilian territory, with an area of $844,453^{\mathrm{km} 2}$, which corresponds to $11.00 \%$ of the national territory, predominant of all states of the Northeast and North region of Minas Gerais [6]. This biome has long been considered poor in biodiversity, however, studies have shown its rich biological diversity. More than 2,000 species of vascular, succulent, woody plants and various species of bees, amphibians, birds and mammals have been recorded. Among several species of caatinga, several plants have antioxidant action and several other biological activities, and are used as a remedy for popular use, with leaves, stems and seeds sold in markets and free fairs [6,7-9].

Thus, it is possible to emphasize the species belonging to the family Caparaceae more precisely the species Capparis flexuosa $\mathrm{L}$. (Caparaceae), which is popularly known as wild beans, stands out for presenting a favorable development in semiarid regions, such as the northeast, and in a dry period the occurrence by biological production is satisfactory of this species. Its morphological characteristics consist of a shrub-tree size of perennial leaves, in the late afternoon insects and bees become attracted by their flowers, because they have the ability to ezalarem odor, more precisely due to the main floral resource that it has nectar [10]. Due to its meliferous relevance, $C$. flexuosa L. is recommended to be cultivated in regions that have as activity the creation and conservation of bees, for the extraction of honey. In addition, this forage exercise an important activity in cattle ranching activities in the northeast, which serve as food for the herds, mainly for sheep and goats, thanks to their resistance to develop in dry periods [11]. 
In traditional medicine, wild beans are presented as a contributor to several diseases, such as: sinusitis through its inhalation, and against snake bite reactions, from the embehest of the liquid resulting from its peel shaved with water. In view of the attributions of wild beans in traditional medicine, it is important to quantify phenolic compounds and flavonoids of the leaves of $C$. flexuosa, given the great biological and pharmacological importance of these bioactive compounds in the human organism [12-15]. Therefore, the objective of this study was to quantify the total phenol and flavonoid content of the leaves of $C$. flexuosa L, using spectrophotometric techniques.

\section{Methodology}

\section{Obtaining the Crude Ethanol Extract}

The leaves were collected, identified, dried at room temperature and subsequently crushed. The extraction of the chemical constituents was performed by macerated in P.A. ethanol for two weeks. The extractor liquid was concentrated in rotaevaporator at a temperature of $45^{\circ} \mathrm{C}$ degrees Celsius, to obtain the crude extract.

\section{Phenolic Compounds - Folin Ciocalteau}

The quantification of phenolic compounds and flavonoids was performed by the analytical method of quantification by external standardization, with the aid of a UV-VIS spectrophotometer. The method for determination of total phenols was adapted from [16], and consists of the reaction of the constituent acids of the folinciocalteau reagent and phenolic or non-phenolic compounds. To quantify the phenol content, a calibration curve of manic acid was performed with concentrations ranging from 0.15 to 0.005 $\mathrm{mg} / \mathrm{mL}$. After preparing the calibration curve, the plant extract solution was prepared. Initially, $0.005 \mathrm{~g}$ of the plant sample was weighed and diluted in $5 \mathrm{~mL}$ of $\mathrm{MeOH}$. Then, a rate of $0.075 \mathrm{~mL}$ of this solution was removed and $0.425 \mathrm{~mL}$ of $\mathrm{MeOH}$ (stock solution) was added. To perform the reading, $100 \mu \mathrm{L}$ of the stock solution, $500 \mu \mathrm{L}$ of folin - Ciocalteau and $6 \mathrm{~mL}$ of Distilled $\mathrm{H} 2$ for each sample were added in amber glass (in triplicate- for eachsample). It was subsequently stirred in the vortex for 1 minute, then $2 \mathrm{~mL}$ of $15 \%$ sodium carbonate was added and stirred again in the vortex for 30 seconds. The last procedure for the preparation of the solutionswas transferred to the solution to a $10 \mathrm{~mL}$ volumetric balloon and the volume was completed with Distilled $\mathrm{H}_{2} \mathrm{O}$; and then the solutions were incubated in the dark for 2 hours. To obtain the white, a solution of $100 \mu \mathrm{L}$ of $\mathrm{MeOH}, 500 \mu \mathrm{L}$ of the Reagent Folin-Ciocalteau and $1 \mathrm{~mL}$ of H2The distilledwas prepared. Soon after, $2 \mathrm{~mL}$ of sodium carbonate was added $15 \%$ and then stirred for 30 seconds in the vortex. Subsequently completed the volume of the solution in a $10 \mathrm{~mL}$ volumetric balloon. The solution was incubated in the dark for 2 hours. Before any reading, the whitepp p zeroe the spectrophotometer was used. A UV-VIS spectrophotometer with a wavelength of $750 \mathrm{~nm}$ was used to read the solutions.

\section{Quantification of Flavonoid Content}

The analysis was adapted to the study by [17]. Initially, the calibration curve was prepared with the quercetin pattern, where $1 \mathrm{mg}$ of quercetin was weighed and diluted in $1 \mathrm{ml}$ of $\mathrm{MeOH}$. Then, dilutions were performed at concentrations of $0.03 ; 0,025 ; 0,020$; 0,$015 ; 0,01 ; 0,005 ; 0.0025$ and $0.00125 \mathrm{mg} / \mathrm{ml}$. Soon after, it weighed it and $1 \mathrm{mg}$ of the crude extract and diluted it in $1 \mathrm{ml}$ of $\mathrm{MeOH}$. After preparing the stock solution, the solutions (in wells - in triplicate) were made for reading that contained $200 \mu$ l of the test solution of the plant sample and $100 \mu \mathrm{l}$ of $2 \%$ aluminumchloride solution. The solution for white (in triplicate) was prepared with $200 \mu \mathrm{l}$ of $\mathrm{MeOH}$ and $100 \mu \mathrm{l}$ of $2 \%$ aluminum chloride methanic solution. Then the well plate was kept in the dark for 30 minutes. After the time, the reading was performed in aPECTrophobimeter UV-VIS at $420 \mathrm{~nm}$. The flavonoid content was determined by interpolation of the average absorbance of the samples against the quercetin calibration curve (replacement of the straight equation) and expressed in mg of EQ (quercetin equivalent) per $g$ of the extract.

\section{Results and Discussion}

Phenolic substances are widely distributed in nature, about 8000 phenolic compounds have been found in plants [18]. These compounds can be classified according to their chemical structure, in classes such as simple phenols, phenolic acids, acetophenones, phenylaacetic acids, hydroxycinamic acids, phenylpropenes, coumarins, xanthones, anthraquinonas, flavonoids among others [19]. One of the most importantclasses of phenolic compounds are flavonoids. This class is widely distributed in the plant kingdom, being found in fruits, seeds, roots, splints, flowers, teas and wines. They are aromatic substances and have basic structure C6-C3-C6, with 15 carbon atoms. The two rings are aromatic (rings $\mathrm{A}$ and $\mathrm{B}$ ) joined by three carbons that form a heterocyclic with ring C [20]. By the Folin-Ciocalteau method, the total phenol content of the extract of $\mathrm{C}$. flexuosa leaves was determined by the spectrophotometric method. The total phenol content was identified by interpolation of the absorbance of the samples against a calibration curve constructed with patterns of lalic acid [21], as shown in Graph 1. 


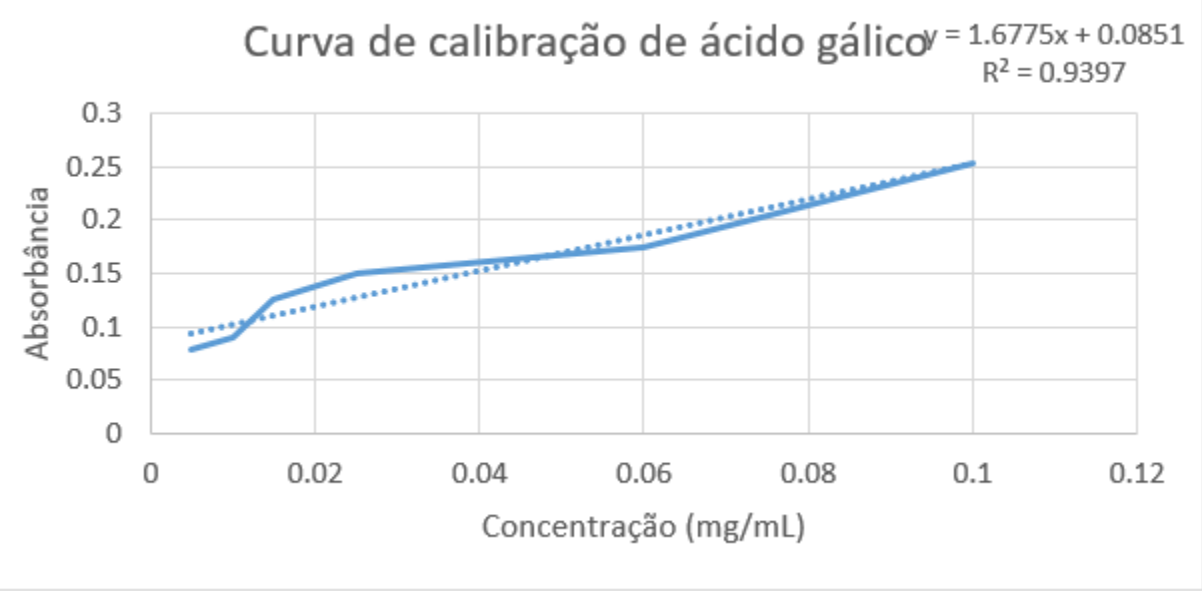

Graph 1: Calibration curve of the lalic acid.

By interpolating the absorbances of the species C. flexuosa, a content of $1916.9 \mathrm{mg}$ EAG/g of extract was obtained; a result being superior to others already described in the literature. According to JUNIOR (2015) [15], when analyzing the wild bean, a phenol content of $595.47 \mathrm{mg} \mathrm{EAG/g}$ of extract was obtained. Assim as phenolic compounds, flavonoids also play an important role in the protection of living organisms against oxidative agents, present in plants, which act as bioactive agents, such as anti-inflammatory, antiallergic, anti-hemorrhagic, action against diabetic retinopathy and among others, highlighting its performance mainly as antioxidant $[8,13,14]$. Thus, there was a quantitative analysis of the flavonoid content of the species $C$. flexuosa, obtaining a content of $84.04 \mathrm{mg} \mathrm{EQ} / \mathrm{g}$ of extract, byinterpolating the absorbances of the sample with a standard quercetin curve (Graph 2).

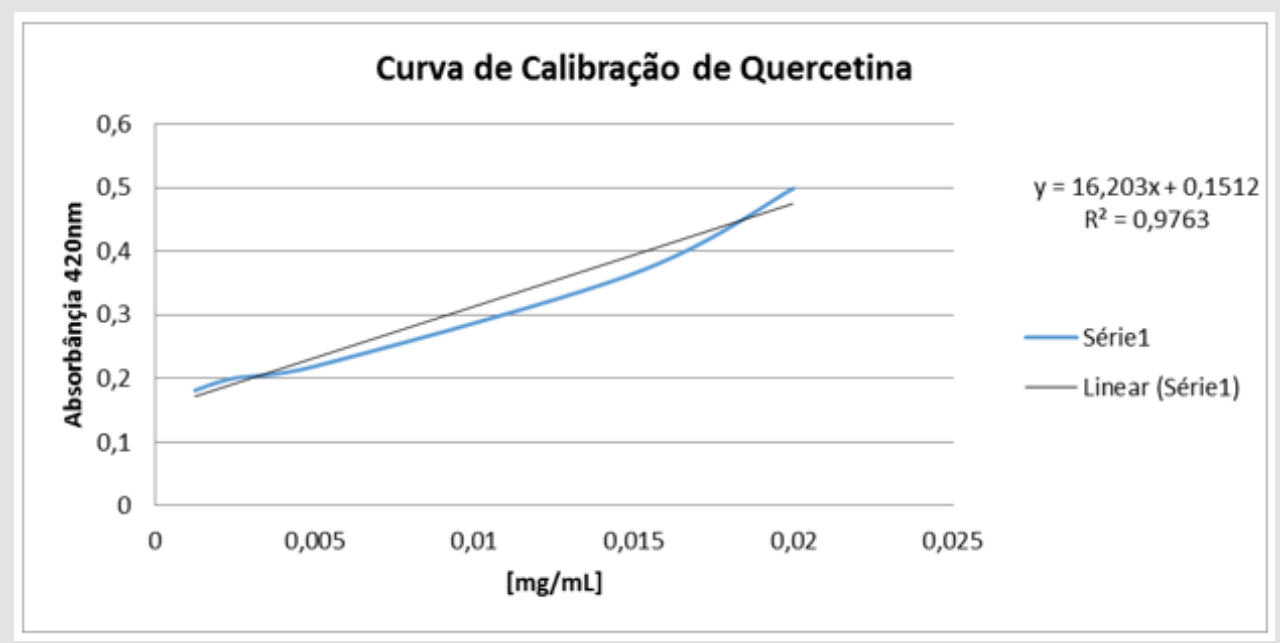

Graph 2: Quercetin calibration curve.

\section{Conclusion}

The preliminary spectrophotometric analysis of the crude extract of the leaves of the species $C$. flexuosa showed significant values of phenolic compounds and flavonoids. Therefore, future studies should promote the identification of compounds and/ or structural isolation and characterization, monitored by pharmacological bioassays, aiming to identify the active ingredients in different experimental models of inflammatory, cardiovascular and metabolic diseases. 


\section{References}

1. Meneguelli AZ, et al. (2018) The Use of Medicinal Plants and Phytotherapeutic Plants In Brazilian Public Health. Journal of Nursing and Collective Health-REVESC 1: 2018.

2. Pinto AC, et al. (2002) Natural products: current affairs, challenges and perspectives. New chemistry 25: 45-61.

3. Viegas JR C et al. (2006) Natural products and modern medicinal chemistry. New Chemistry 29: 326-337.

4. Nunes JD, Maciel MV (2017) The importance of nursing professional information on care in the use of medicinal plants: a literature review. Fitos Eletrônica Magazine10: 518-525.

5. Ribeiro DA, et al. (2014) Therapeutic potential and use of medicinal plants in an area of Caatinga in the state of Ceará, northeastern Brazil. Revista Brasileira de Plantas Medicinais, Campinas 16: 912-930.

6. Silva MF, et al. (2016) An analysis of the caatinga biome in the municipality of Gado Bravo-PB through the Normalized Difference Vegetation Index.

7. Santos CA, Cunha AL, Da Costa MLA, De Almeida AS, Da JM, et al. (2021) Analysis of antioxidant activity and phytochemical profile of the leaf, stem and inflorescence of Senna splendida. Diversitas Journal 6: 769782.

8. Silva JA, et al. (2021) Phytochemical prospecting and determination of the antioxidant potential in vitro of Licania tomentosa (Benth.) Diversitas Journal 6: 2099-2108.

9. Almeida AS, Santos AF (2018) Anticolinestersic potential of plants of the Caatinga biome: a review. Diversitas Journal 3: 505-518.

10. Barreto GP (2005) Use of wild bean hay (Capparis flexuosa L.) in diets for Santa Inês sheep. Sand-PB.

11. Silva MJD, et al. (2012) Evaluation of antioxidant and antimicrobia activity of extracts and organic fractions of Mimosa caesalpinifolia Benth (Mimosaceae). Journal Basic Applied Pharmaceutical Science 33: no 2 .

ISSN: 2574-1241

DOI: $10.26717 / B J S T R .2021 .39 .006358$

Anderson Soares de Almeida. Biomed J Sci \& Tech Res

CC (P) This work is licensed under Creative Commons Attribution 4.0 License

Submission Link: https://biomedres.us/submit-manuscript.php
12. Nicolaides AN (2020) The Benefits of Micronized Purified Flavonoid Fraction (MPFF) Throughout the Progression of Chronic Venous Disease.

13. Matos AL, Bruno DF, Ambrosio AF, Santos PF (2020)The benefits of flavonoids in diabetic retinopathy. Nutrients 12(10): 3169.

14. Yadav M, et al. (2020) Cardioprotective and hepatoprotective potential of citrus flavonoid naringin: Current status and future perspectives for health benefits. Asian Journal of Biological and Life Sciences 9: 1.

15. Junior JCC, Melo PLM, Silva KB, Oliveira JDS, Gomes TCA, et al. (2015) Phenols and flavonoids in wild beans(Capparis flexuosa) and mororó(Bauhinia cheilantha)in Háplic planossols of the alagoas semiarid region.

16. Alves E, Kubota EH (2013) Phenolic content, total flavonoids and antioxidant activity of commercial propolis samples. Journal of Basic and Applied Pharmaceutical Sciences 34: 2013

17. Souza LB, et al. (2011) Quantification of flavonoids in the roots of Urera baccifera gaudich (Urticaceae). Revista Contexto \& Saúde 11:1287-1290.

18. Silva MLC, Costa RS, Santana ADS, Koblitz MGB, et al. (2010) Phenolic compounds, carotenoids and antioxidant activity in plant products. Phenolic compounds, carotenoids and antioxidant activity in plant products Week: Agrarian Sciences Londrina 31: 669-682.

19. Efraim P, et al. (2011) Review: Polyphenols in cocoa and derivatives: contents, variation factors and health effects. Brazilian Journal of Food Technology 14: 181-201.

20. Coutinho MAS, et al. (2009) Flavonoids: Potential therapeutic agents for the inflammatory process. Virtual Journal of Chemistry 1: 241-256.

21. Rezende LC (2010) Evaluation of antioxidant activity and chemical composition of six tropical fruits consumed inBahia. Doctoral thesis, Graduate Program in Chemistry, Federal University of Bahia, SalvadorBA.

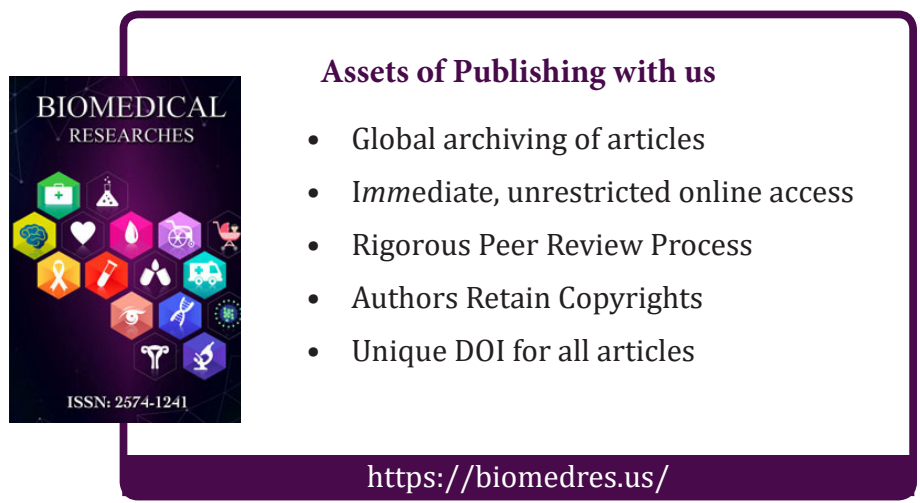

